\title{
Rancang Bangun Generator Thermal Dengan Pemanfaatan Limbah Panas Knalpot Motor Replika
}

\author{
Alhidayat $^{1}$, Syaiful Bakhri ${ }^{2}$, Seflahir Dinata ${ }^{3}$, \\ [Submission: 17-01-20219, Accepted: 27-02-021]
}

\begin{abstract}
Thermoelectric power plants are solid state devices that provide direct energy conversion from thermal energy due to a temperature gradient into electrical energy based on the "Seebeck effect", working by converting heat energy into electricity directly. In "Design of Thermal Generator with the Utilization of Heat Exhaust from Motor Replica". The test uses 4, TEP1-142 T300 in series, the test is carried out in several stages, namely no-load testing, the highest voltage obtained reaches 8 volts at $(\Delta T)$ the temperature difference between $\mathrm{TH}$ and TL $31^{\circ} \mathrm{C}$, the temperature is $\mathrm{TH} 65^{\circ} \mathrm{C}$ and the temperature TL $34{ }^{\circ} \mathrm{C}$. then using a load of 5 watt led lights experiencing a voltage drop, the maximum voltage is 5 volts with the power obtained 0.41 watts at 0.07 amperes, the test uses a boost converter, the voltage is as stable as 5 volts, where the thermoelectric voltage is $V$-in. must get a voltage of 3 volts.

In this test the thermoelectric generator generates electrical power which is influenced by the temperature difference between TH and TL where the TL temperature must be lower than TH to get high power, the temperature at TL must always be maintained, therefore a good temperature cooling radiator is needed at TL, which is not more than $40{ }^{\circ} \mathrm{C}$, the power generated can only turn on a 5 volt lamp with a power of 0.34 watts which is very small because the number of thermoelectric modules also affects the power produced, the advantage in this test is that we can take advantage of the exhaust heat of motorized vehicles.
\end{abstract}

Intisari- Pembangkit listrik thermoelectric adalah perangkat solid state yang menyediakan konversi energi langsung dari energi panas karena gradien suhu menjadi energi listrik berdasarkan "efek Seebeck", bekerja dengan mengkonversi energi panas menjadi listrik secara langsung, dalam "Rancang Bangun Generator Thermal Dengan Pemanfaatan Limbah Panas Knalpot Motor Replika".

Pengujian mengunakan TEP1-142 T300 sebanyak 4 buah di susun seri, pengujian dilakukan beberapa tahapan yakni pengujian tanpa beban, tegangan tertinggi yang di dapatkan mencapai 8 volt pada perbedaan suhu $(\Delta T)$ antara TH dan TL adalah $31{ }^{\circ} \mathrm{C}$ suhu di TH $65{ }^{\circ} \mathrm{C}$ dan suhu TL $34{ }^{\circ} \mathrm{C}$, Selanjutnya menggunakan beban lampu led 5 volt mengalami drop tegangan, tegangan maksimal yang di dapatkan 5 Volt dengan daya listrik yang di dapatkan 0,41 Watt di arus 0,07 Ampere, pengujian menggunakan boost converter tegangan pada V-out stabil

\footnotetext{
${ }^{1}$ Mahasiswa, Jurusan Teknik Elektro Fakultas Teknik Universitas Universitas Pamulang, Jalan Raya Puspiptek, Buaran, Kec. Pamulang, Kota Tangerang Selatan, Banten 15310;021-7412566; e-mail: alhidayat_mail@gmail.com)

${ }^{2,3}$ Dosen, Jurusan Teknik Elektro Fakultas Teknik Universitas Universitas Pamulang, Jalan Raya Puspiptek, Buaran, Kec. Pamulang, Kota Tangerang Selatan, Banten 15310; 0217412566;e-mail:2dosen00047@unpam.ac.id,

${ }^{3}$ dosenunpam01138@unpam.ac.id
}

mendapatkan 5 Volt, dimana tegangan thermoelectric V-in harus mendapatkan tegangan 3 Volt.

Pada pengujian ini thermoelectric generator menghasilkan daya listrik di pengaruhi dari perbedaan suhu antara TH dan TL di mana suhu TL harus lebih rendah dari TH untuk mendapatkan daya yang tinggi, suhu di TL harus selalu tetap terjaga maka dari itu di perlukan radiator pendingin suhu yang baik pada TL yakni tidak lebih dari $40^{\circ} \mathrm{C}$, daya yang di hasilkan hanya dapat menyalakan lampu 5volt dengan dengan daya 0,34 watt sangat kecil sekali karena jumlah modul thermoelectric juga mempengaruhi daya yang dihasilkan, kelebihan dalam pengujian ini kita dapat memanfaatkan panas buang kendaaraan bermotor.

Kata Kunci- Thermoelectric, Generator thermal, Limbah panas.

\section{PENDAHULUAN}

Dalam beberapa tahun terakhir perkembangan teknologi energi banyak mengalami kemajuan dalam pengembangan alat pembangkit listrik, sangat dibutuhkan pemahaman terkait design alat agar mendapatkan hasil yang optimal.

Telah banyak pengembangan energi alternatif pembangkit listrik yang di produksi seperti solar cell yang dapat mengkonversikan energi surya dan panas matahari menjadi listrik, energi panas tidak hanya dapat diciptakan oleh panas matahari, salah satunya juga ada limbah panas yang di hasilkan oleh kompor maupun mesin pembakaran internal yang efisien.[1]

Pemanfaatan limbah panas kendaraan bermotor untuk Generator listrik Thermoelectric telah muncul sebagai alternatif teknologi hijau di mana tidak perlu mempertimbangkan biaya input energi panas,[2] ada sekitar $40 \%-70 \%$ energi panas hilang melalui sistem pembuangan mesin bensin dari sebagian besar kendaraan.[3] Untuk mengurangi penggunaan bahan bakar dan meningkatkan efisiensi kendaraan, membuang panas ditransmisikan ke sisi panas Generator listrik Thermoelectric, yaitu dipasang di permukaan sistem pembuangan.[4]

Generator thermal memakai modul yang disebut Thermoelectric generator (TEG), juga disebut generator Seebeck, adalah perangkat solid state yang mengubah fluks panas (perbedaan suhu) langsung menjadi energi listrik.[5] Generator Thermoelectric berfungsi seperti mesin pemanas, tetapi tidak terlalu besar dan tidak memiliki bagian yang bergerak. Namun, TEG biasanya lebih mahal dan kurang efisien.[6] Generator listrik Thermoelectric akan menjadi salah satu perangkat paling penting dan luar biasa di masa depan.[7] 
Pemanfaat panas limbah dalam pengujian ini memakai kenalpot replica agar lebih mudah mensimulasikan kedalam kendaraan bermotor, bersifat prototype.

\section{TINJAUAN PUSTAKA}

\section{A. Teknologi Thermoelectric}

Teknologi Thermoelectric bekerja dengan mengkonversi energi panas menjadi listrik secara langsung atau sebaliknya, dari listrik menghasilkan dingin,[8] untuk menghasilkan listrik, material Thermoelectric cukup diletakan sedemikian rupa dalam rangkaian yang menghubungkan sumber panas dan dingin.

\section{B. Energi panas}

Energi termal adalah jenis energi yang berkaitan dengan getaran atomik dan molekular.[9] Energi jenis ini adalah bentuk energi dasar dengan arti kata, semua bentuk energi lain dapat dikonversi secara penuh ke energi ini, tetapi pengkonversi energi termal menjadi bentuk energi lain dibatasi oleh hukum kedua termodinamika. [10]

\section{Perpindahan panas}

Perpindahan panas atau kalor dari suatu zat ke zat lain seringkali terjadi dalam proses industri. Perpindahan panas adalah salah satu dari disiplin ilmu teknik termal yang mempelajari cara menghasilkan panas, mengubah panas, dan menukarkan panas di antara sistem fisik.[11] Perpindahan panas di klasifikasikan menjadi konduktivitas termal, konveksi termal, dan radiasi termal

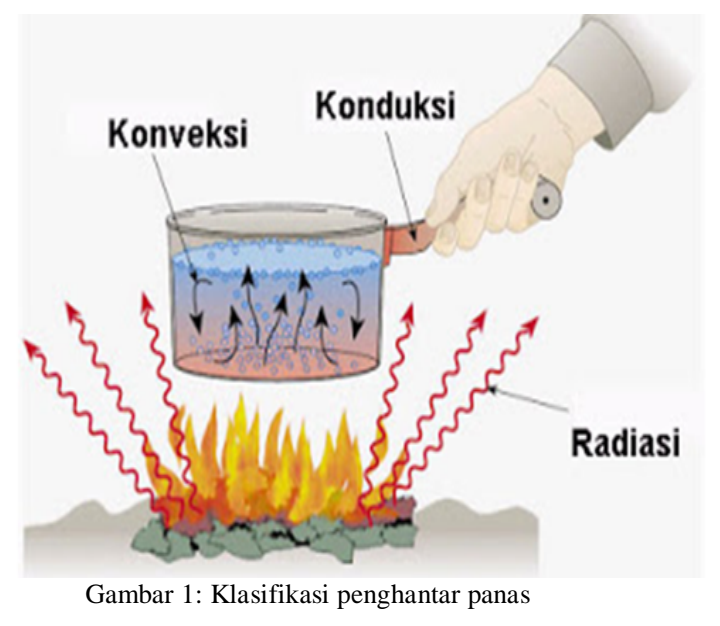

1) Konduksi : Konduksi panas muncul sebagai "rasa panas", atom yang bergetar atau berpindah sedemikian cepat berinteraksi dengan atom dan molekul sekelilingnya sehingga memindahkan sejumlah energi mereka ke partikel di sekelilingnya. [12]

2) Konveksi : Perpindahan panas konveksi adalah perpindahan panas dari satu tempat ke tempat lain karena adanya perpindahan fluida, proses perpindahan panas melalui perpindahan massa, gerak serempak fluida menambah perpindahan panas pada banyak kondisi, seperti misalnya antara permukaan solid dan permukaan fluida. [13]
3) Radiasi: Radiasi termal adalah energi yang dilepaskan oleh benda sebagai gelombang elektromagnetik, karena adanya tumpukan energi termal pada semua benda dengan suhu di atas nol mutlak. [13]

Tidak seperti konduksi dan konveksi, radiasi termal dapat dikumpulkan di sebuah titik kecil menggunakan kaca pemantul, kemudian dimanfaatkan untuk pembangkit listrik solar. [14]

\section{Efek Seebeck}

Ketika perbedaan suhu terjadi antara sambungan panas dan dingin dari dua bahan yang berbeda (logam atau semikonduktor) tegangan yang dihasilkan, yaitu, tegangan Seebeck. Bahkan, fenomena ini diterapkan untuk termokopel yang banyak digunakan untuk pengukuran suhu. Berdasarkan efek Seebeck ini, perangkat Thermoelectric dapat bertindak sebagai generator tenaga listrik.[15]

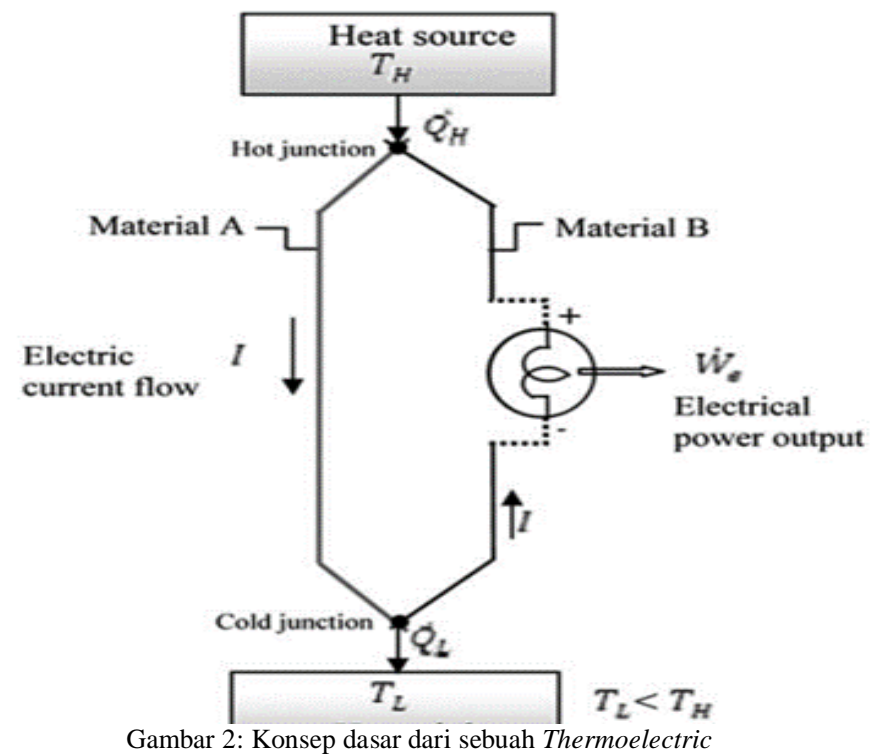

Panas dipindah kan pada tingkat $\mathrm{Q}_{\mathrm{H}}$ dari panas suhu tinggi sumber di pertahankan $T_{H}$ kesimpangan panas di tolak pada tingkat $\mathrm{Q}_{\mathrm{L}}$ untuk sink daya rendah $\mathrm{T}_{\mathrm{L}}$ dari persimpangan dingin, berdasar kan efek seeback, panas yang disediakan persimpangan menyebabkan arus listrik mengalir di sirkuit dan daya listrik di hasilkan.

Menggunakan hukum termodinamika (prinsip konversi energi), perbedaan antara $\mathrm{Q}_{\mathrm{H}}$ dan $\mathrm{Q}_{\mathrm{L}}$ adalah output daya listrik $\mathrm{W}_{\mathrm{B}}$ perlu dicatat siklus kekuasaan erat menyerupai siklus kekuatan mesin, sehingga dalam hal ini generator listrik Thermoelectric dapat dianggap sebagai mesin panas yang unik. [16]

Kinerja Thermoelectric dapat di nyatakan dengan [17]:

$$
Z=\frac{\alpha^{2}}{k R}
$$

Dimna $\mathrm{Z}$ adalah bahan Thermoelectric figure-of-merit, $\alpha$ adalah koefesinsi seeback yang di berikan oleh,[18]

$$
\alpha=\frac{\Delta V}{\Delta T}
$$


$\mathrm{R}$ adalah resitivitas listrik (kebalikan dari konduktivitas listrik) dan $\mathrm{K}$ adalah konduktivitas thermal keseluruhan, figurof-merit ini dapat dibuat tanpa dimensi dengan mengalikandengan $\bar{T}$ (suhu absolut rata-rata pelat panas dan dingin dari modul Thermoelectric, K), yaitu :

$$
Z \bar{T}=\frac{\alpha^{2} \bar{T}}{k R}
$$

dan,

$$
\bar{T}=\frac{T H+T L}{2}
$$

Syarat $\frac{\alpha^{2}}{R}$ disebut sebagai tenaga listrik faktor. Secara umum, pembangkit listrik Thermoelectric pameran efisiensi rendah karena relatif berdimensi kecil $(Z \bar{T}=\leq 1)$ bahan Thermoelectric yang tersedia saat ini.

\section{METODOTOLOGI PENELITIAN}

\section{A. Tahap penyiapan prototipe Thermoelectric generator}

Prinsip kerja dari thermoelectric adalah dengan berdasarkan efek Seebeck yaitu jika dua buah logam yang berbeda disambungkan salah satu ujungnya, kemudian di beri suhu yang berbeda pada sambungan, maka terjadi perbedaan tegangan pada ujung yang satu dengan ujung yang lainya [19], dalam gambar 3. cara kerja thermoelectric generator di bawah ini.

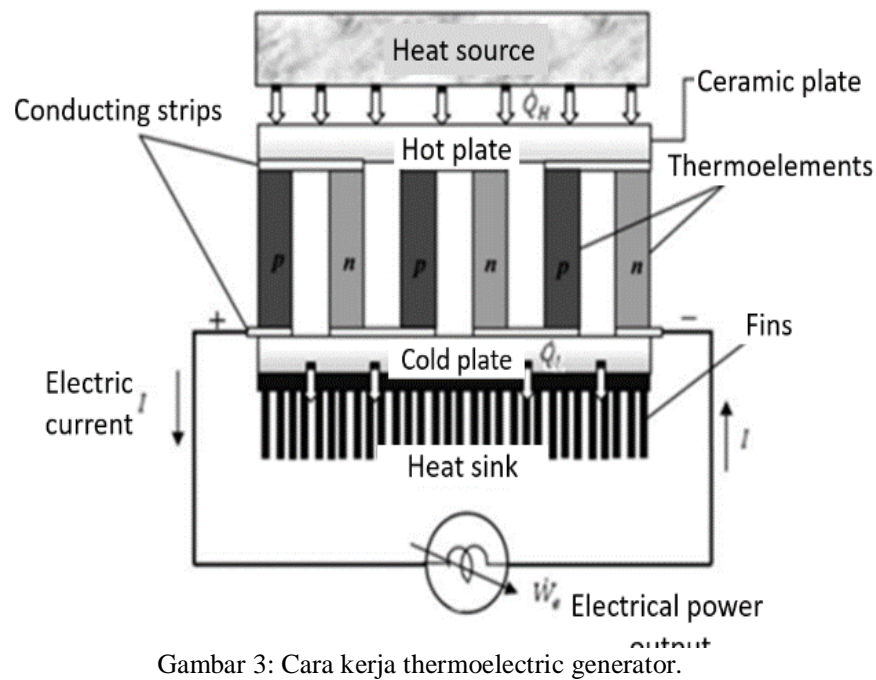

Thermoelectric yang di pakai dalam penelitian ini adalah Thermoelectric type TEP1-142 T300 sebanyak 4 buah, di susun seri agar menghasilkan tegangan listrik yang lebih tinggi.
Cooling water radiator

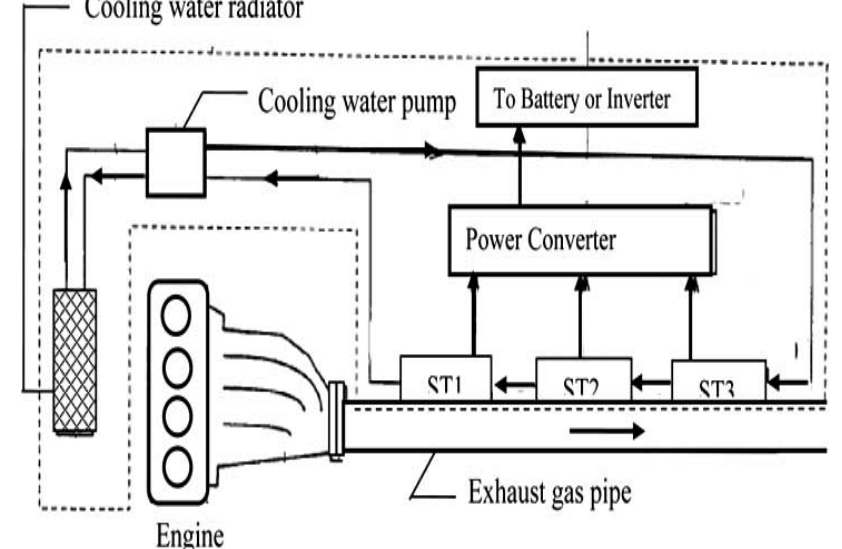

Gambar 4: Diagram skematik paten baru yang diterapkan pada mobil untuk mengubah limbah panas langsung menjadi tenaga listrik generator listrik termoelektrik. [20]

Bedasarkan konsep pada gambar 4. Diagram skematik paten baru yang diterapkan pada mobil untuk mengubah limbah panas langsung menjadi tenaga listrik generator listrik termoelektrik, [20], yang akan diterapkan dalam penyiapan prototipe generator thermal dengan pemanfaatan limbah panas memakai modul Thermoelectric generator, penelitian di bagi dua tahapan yaitu dengan pengujian tanpa boost converter dapat dilihat pada gambar 5 dan pengujian dengan boost converter dapat dilihat pada gambar 6.

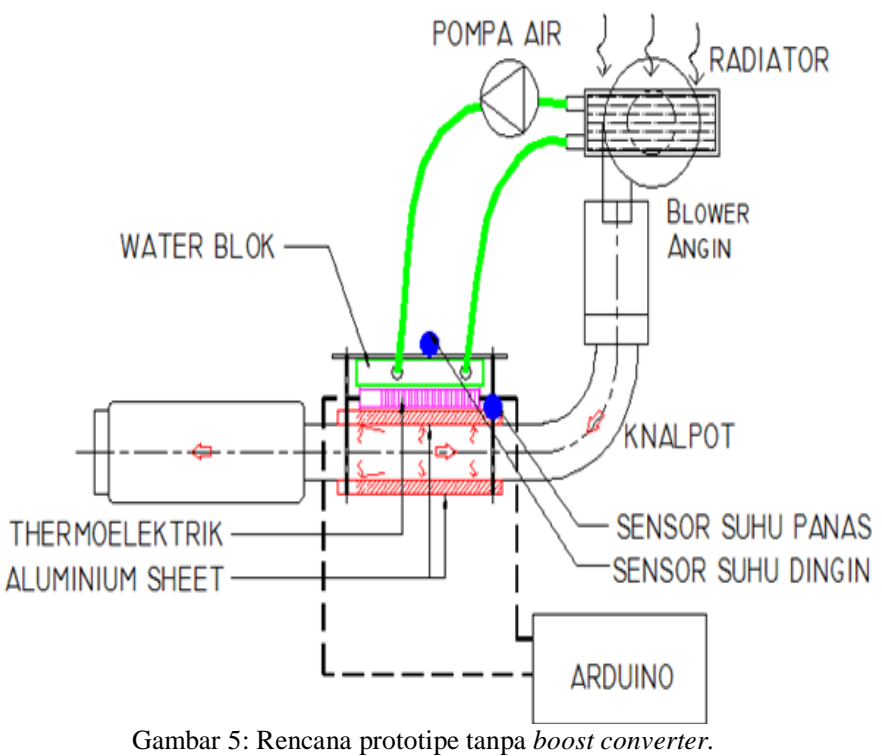




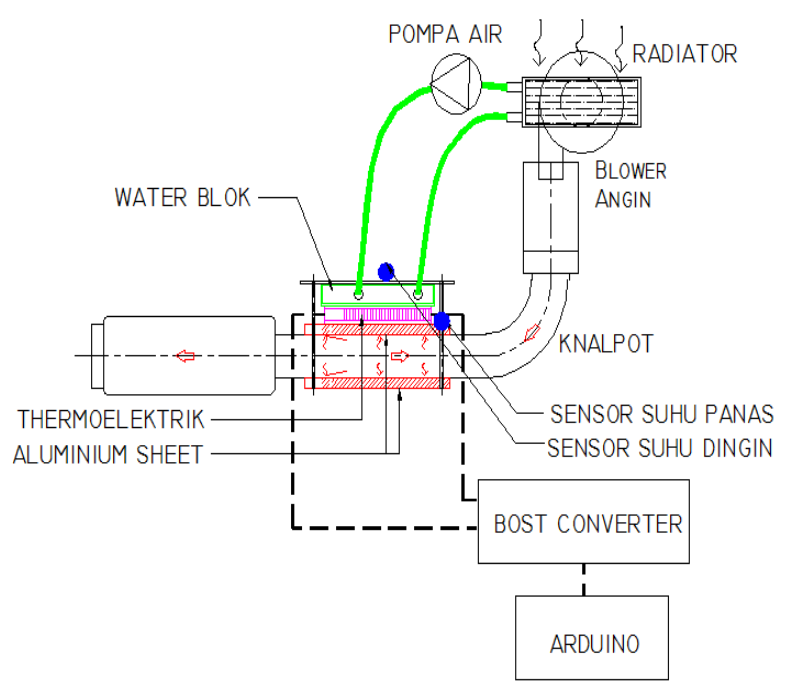

Gambar 6: Rencana prototipe dengan boost converter.

Pemasangan Thermoelectric di alaskan oleh aluminium sheet agar panas yang diterima oleh Thermoelectric merata dan pada sisi dingin Thermoelectric terdapat waterblok yang terkoneksi dengan radiator melalui selang air sebagai pendingin dari Thermoelectric, air bersikulasi dengan bantuan pompa air micro, pemasangan Thermoelectric, waterblok dan aluminum sheet di couple dengan baut, Thermoelectric di rangkai seri agar bertujuan untuk mendapatkan besaran tegangan (lihat gambar 7.).

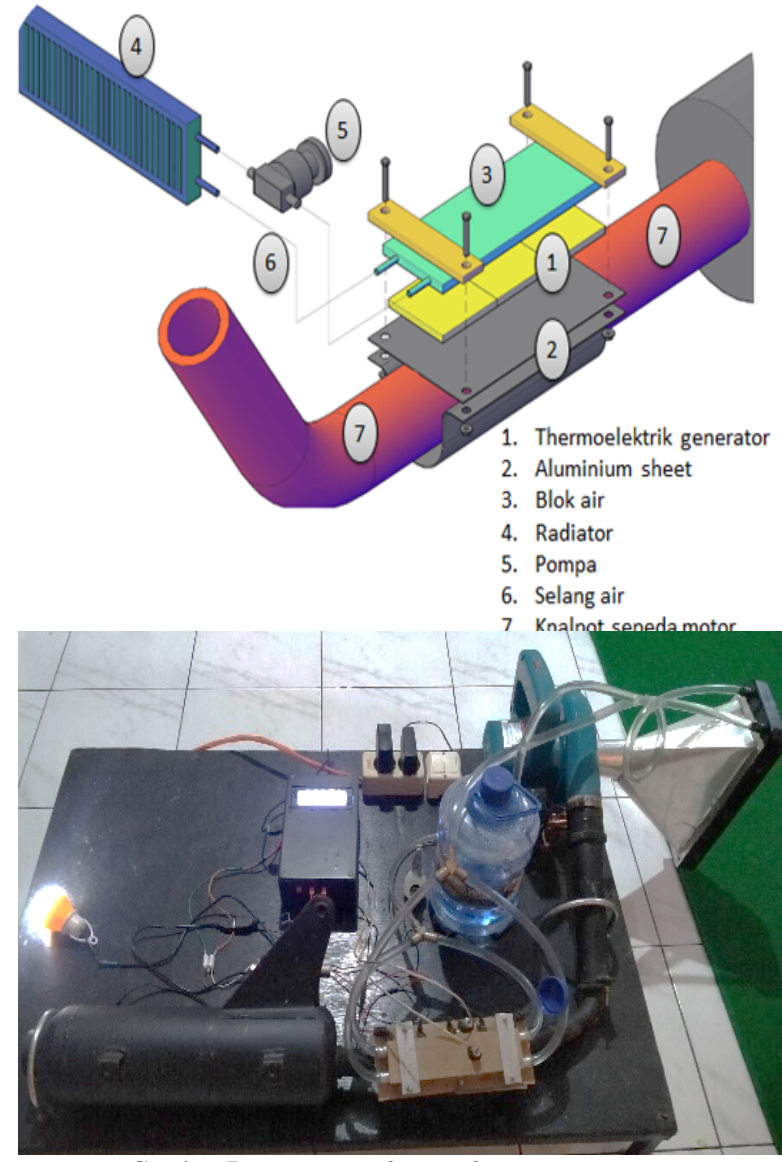

Gambar 7: Prototype Thermoelectric generator

\section{B. Tahap perancangan alat uji data logger dengan Arduino}

Perancangan alat uji dengan microcontroler arduino yang dapat menyimpan data atau yang di sebut data logger, yang nantinya alat uji tersebut bisa menyimpan data uji seperti temperatur panas, tegangan, dan arus listrik, yang nantinya data tersebut di gunakan untuk menganalisa dari kinerja Thermoelectric generator, di bawah ini adalah Gambar 8 . merupakan diagram perancang alat uji microcontroller arduino.
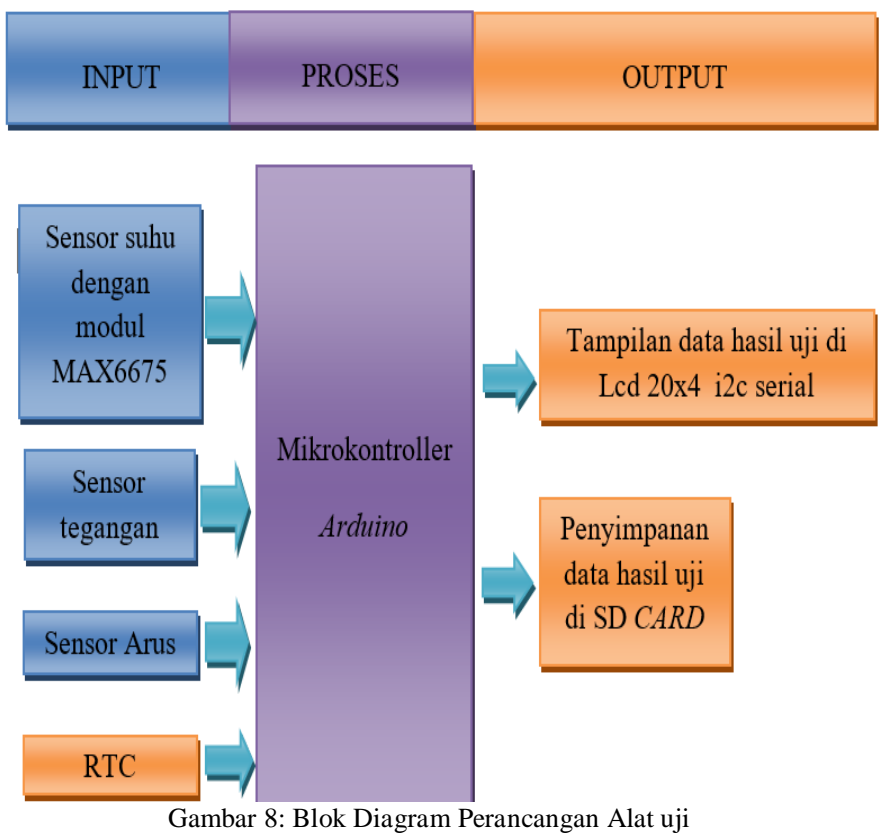

\section{Alat dan Bahan}

Pembuatan prototype Thermoelectric generator dengan pemanfaatan limbah panas knalpot sepeda motor membutuhkan alat dan bahan, dalam mennetukan alat dan bahan penelitian ini di bagi tiga bagian yaitu bahan pembuatan prototype Thermoelectric generator, bahan pembuatan alat uji dengan matrial utama microcontroler arduino yang dapat menyimpan data uji, dan alat ukur serta alat bantu yang di perlukan.

TABEL I

Bahan Pembuatan Prototype

\begin{tabular}{|c|c|c|}
\hline No. & Bahan & Jumlah \\
\hline 1 & TEG type TEP1-142 T300 & 4 bh \\
\hline 2 & Buck Boost converter & 1 bh \\
\hline 3 & Aluminium sheet & $1 \mathrm{lbr}$ \\
\hline 4 & PC Radiator & 1 bh \\
\hline 5 & Water block & $1 \mathrm{bh}$ \\
\hline 6 & Pompa air micro & 1 bh \\
\hline 7 & Selang air & $1 \mathrm{~m}$ \\
\hline 8 & Knalpot sepeda motor & $1 \mathrm{bh}$ \\
\hline 9 & Element heater heat gun & 1 bh \\
\hline 10 & Mesin blower type NRT-4014HD & $1 \mathrm{bh}$ \\
\hline
\end{tabular}


Majalah Ilmiah Teknologi Elektro, Vol. 20, No.1, Januari-Juni 2021

DOI: https://doi.org/10.24843/MITE.2021.v20i01.P08

TABEL III

Bahan Pembuatan Alat Uji

\begin{tabular}{|c|l|cc|}
\hline No. & \multicolumn{1}{|c|}{ Bahan } & \multicolumn{2}{c|}{ Jumlah } \\
\hline 1 & Arduino Mega 2560 & 1 & bh \\
\hline 2 & Thermocouple type K dan MAX6675 & 2 & bh \\
\hline 3 & Sensor arus INA219 & 1 & bh \\
\hline 4 & Sensor tegangan & 2 & br \\
\hline 5 & Modul Real Time Clock DS323 & 1 & bh \\
\hline 6 & SD card Shield & 1 & bh \\
\hline 7 & Lcd 20x4 i2c serial connection & 1 & bh \\
\hline
\end{tabular}

TABEL III

ALAT UKUR DAN ALAT BANTU

\begin{tabular}{|c|c|c|}
\hline No & Alat ukur dan alat bantu & Jumlah \\
\hline 1 & Tang amper & 1 bh \\
\hline 2 & Multitester & 1 bh \\
\hline 3 & Anemometer & bh \\
\hline 4 & Thermometer & $1 \mathrm{bh}$ \\
\hline 5 & Kabel & $1 \quad$ lot \\
\hline 6 & Kabel jamper arduino & 1 lot \\
\hline 7 & Solder dan timah & $1 \mathrm{bh}$ \\
\hline 8 & Penyedot timah & bh \\
\hline 9 & Obeng plus minus & $1 \mathrm{bh}$ \\
\hline 10 & Tang kombinasi & $1 \mathrm{bh}$ \\
\hline 11 & Tang potong & $1 \mathrm{bh}$ \\
\hline 12 & Pisau cutter & $1 \mathrm{bh}$ \\
\hline 13 & Pasta thermal & $1 \mathrm{bh}$ \\
\hline
\end{tabular}

\section{HASIL DAN PEMBAHASAN}

A. Pengukuran keluaran angin pada knalpot sepeda motor spacy

Pengukuran keluar angin pada knalpot sepeda motor dilakukan dengan alat Anemometer alat untuk mengukur kecepatan angin, dengan satuan kecepatan angin yang di gunakan adalah $\mathrm{Km} / \mathrm{Jam}$ (Kilometer per jam).

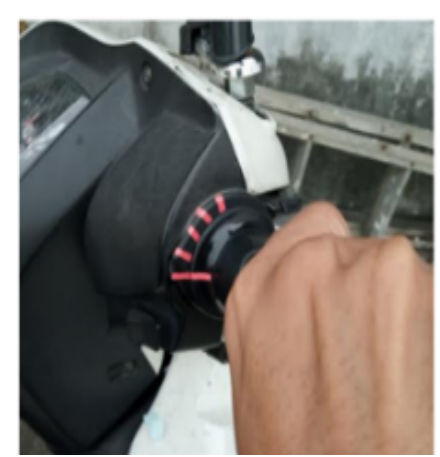

Gambar 9: Pengambilan data kecepatan angin dengan alat anemometer

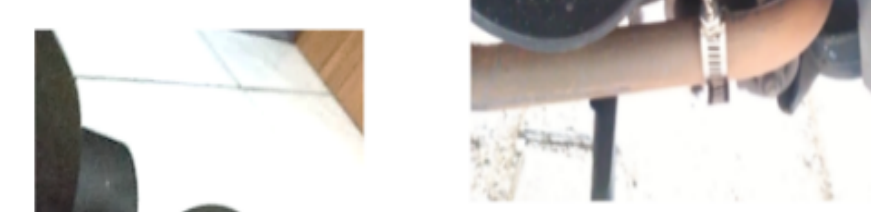

$(n)$

Gambar 11: Penempatatan sensor thermocouple

pengukuran dilakukan dengan 5 posisi pengaturan handle gas yang hasil pengambilan data di masukan dalam grafik pada gambar 10.di bawah ini.

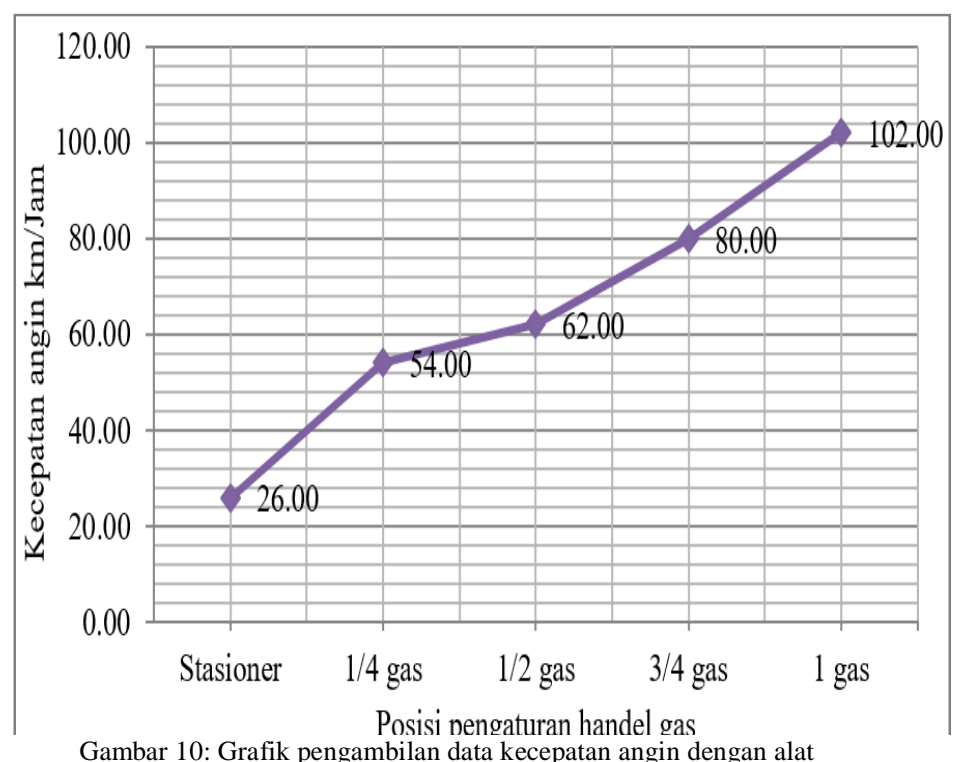

Gambar 10: Grafik pengambilan data kecepatan angin dengan alat anemometer

Grafik (Gambar 10) hasil dari pengukuran kecepatan angin di dapatkan kecepatan angin yang di hasilkan oleh keluaran knalpot sepeda motor spacy, kecepatan meningkat sesuai dengan posisis pengaturan handel gas makin tinggi posisi pengaturan handel gas makin cepat juga laju udara yang keluar dari knalpot sepeda motor.

B. Pengukuran suhu pada saat sepeda motor di hidupkan kondisi standbay dan berjalan

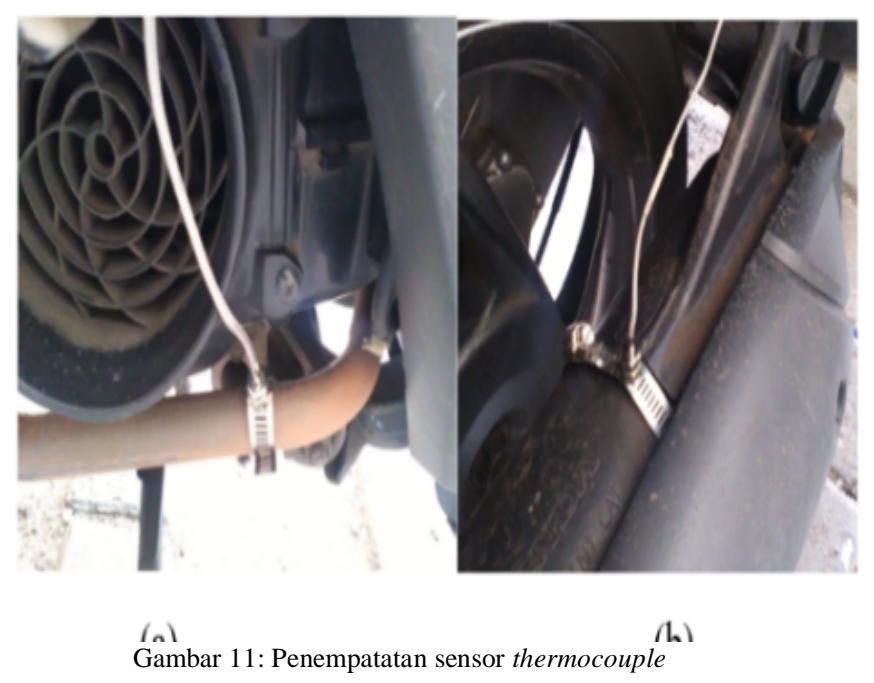

Dalam pengukuran suhu knalpot motor di lakukan di dua titik di leher knalpot titik a dan di silencer knalpot titik b. di lihat pada Gambar 11.

Pengukuran suhu panas pada knalpot sepeda motor dalam kondisi di hidupkan, perbandingan dapat dilihat dalam gambar 12. dibawah ini.

p-ISSN:1693 - 2951; e-ISSN: 2503-2372

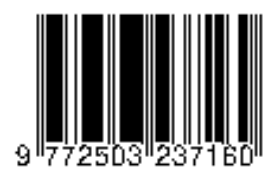




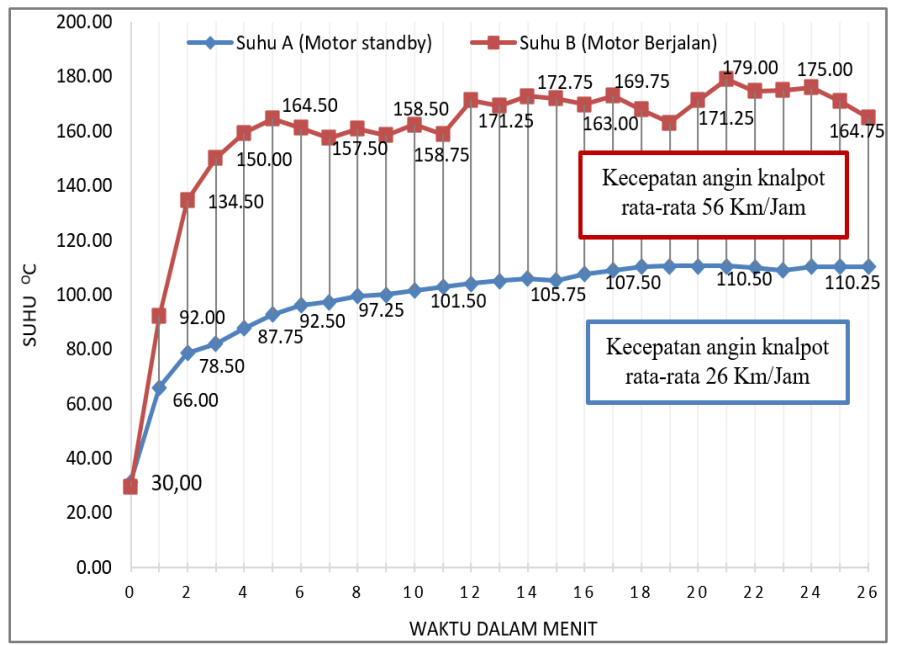

Gambar 12: Grafik perbandingan suhu knalpot sepeda motor di hidupkan kondisi standbay dan dikendarai berjalan.

Pada gambar 12. perbandingan suhu knalpot sepeda motor di hidupkan standby suhu A dan motor di hidupkan kondisi dikendarai berjalan suhu B, dalam grafik dapat di lihat suhu B lebih tinggi di bandingkan dengan suhu A, pada saat pangambilan data suhu A sepeda motor standby panas motor naik secara stabil karena dalam pembakaran mesin motor aliran udara dan pembakaran bahan bakar dalam mesin sepeda motor berjalan stabil memiliki alur nya atau bisa di bilang alur yang konstan, sedangkan suhu B yaitu suhu pada leher knalpot pada saat motor hidupkan di kendarai berjalan pembakaran yang cepat karena pengaturan handel gas mengakibatkan panas cepat naik.

Pengukuran kecepatan angin dan pengukuran suhu panas knalpot pada motor spacy (motor sungguhan) data yang di dapatkan bertujuan untuk di implementasi ke dalam knalpot replika.

\section{Pengujian pada prototype knalpot replika.}

Pengaturan aliran udara atau kecepatan laju udara keluaran knalpot sepeda motor di atur oleh pengaturan handle gas, sedang kan pada knalpot replika diatur oleh blower tangan yang memiliki indikator kecepatan 6 kecepatan semakin level indikator naik laju angin semakin cepat.
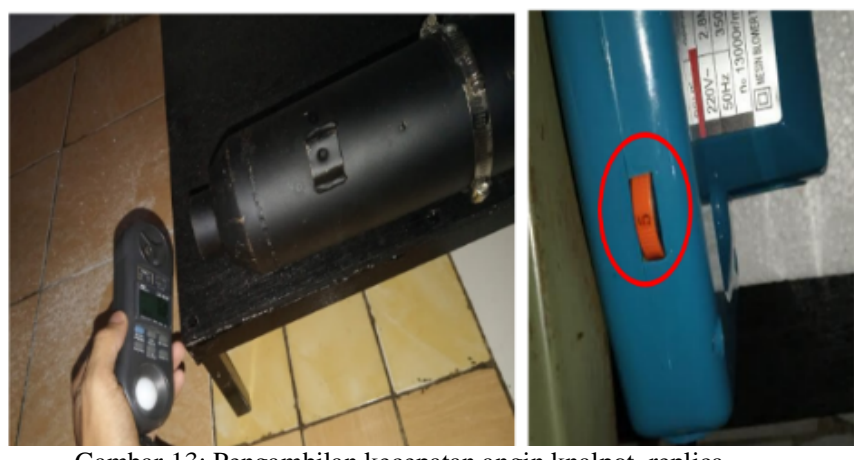

Gambar 13: Pengambilan kecepatan angin knalpot replica

Dari hasil percobaan pengukuran aliaran laju angin yang keluar pada prototype knalpot maka akan mendapatkan persamaan dengan keluaran knalpot kendaraan pada gambar 14. dibawah ini

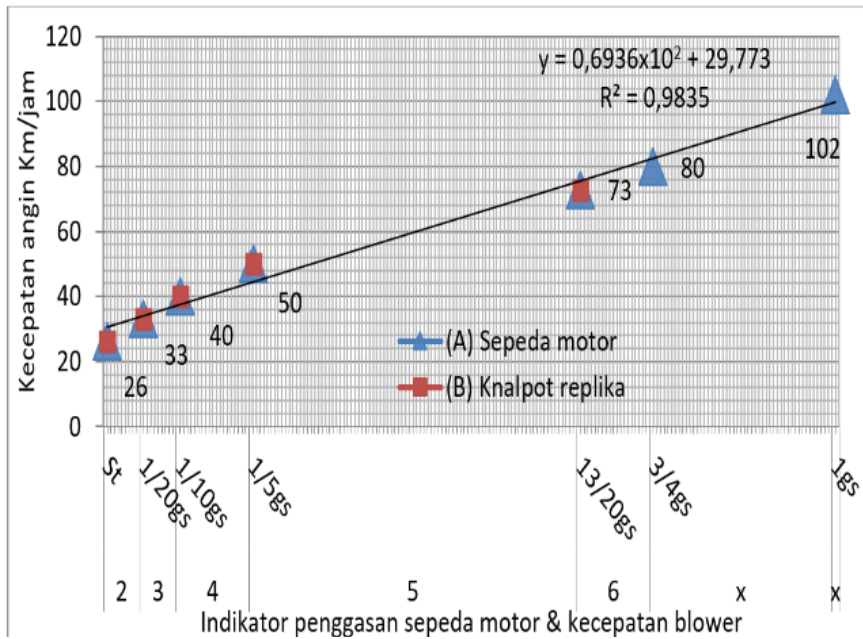

Gambar 14: Grafik persamaan kecepatan angin pada knalpot replika dan knalpot sepeda motor.

Gambar 14. untuk laju aliran angin yang keluar dari knalpot sepeda motor sungguhan adalah di beri nama kecepatan A, sedang kan pada knalpot replika di beri nama kecepatan B, laju aliran udara yang keluara dari dua knalpot yang berbeda kecepatanya laju angin di pengaruhi oleh indikator dan pengaturan handel gas semakin tinggi nialinya semakin tinggi juga kecepatan angin yang keluar dari knalpot, dari hasil pengujian knalpot replika mendekati kemiripan dengan knalpot sepeda motor sesungguhnya dengan persamaan nya $(\mathrm{y}=0,6936 \times 102+29,773)$, koefisien determinasi $\mathrm{R} 2=0,98$.

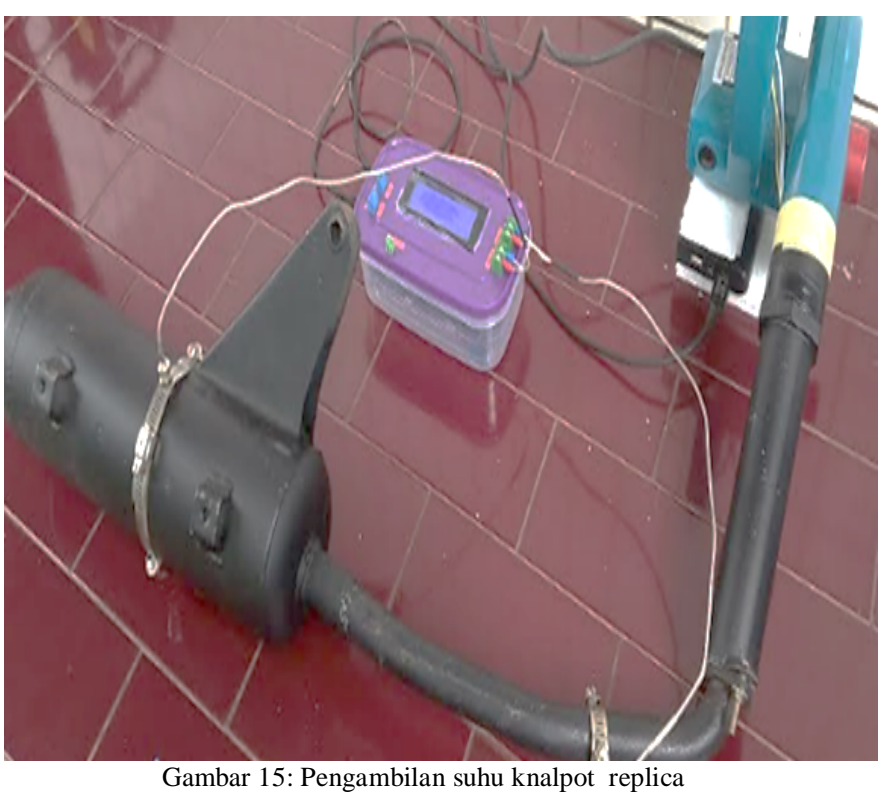

Penempatan thermocouple pengukuran suhu di tempatkan di dua titik yakni di leher knalpot dan silencer knalpot pada gambar 15. Hasil pengukuran suhu pada knalpot replika dapat dilihat pada gambar 16. dan 17. berbentuk grafik, pengujian di lakukan dengan kecepatan blower ke-1 dan ke-3. 


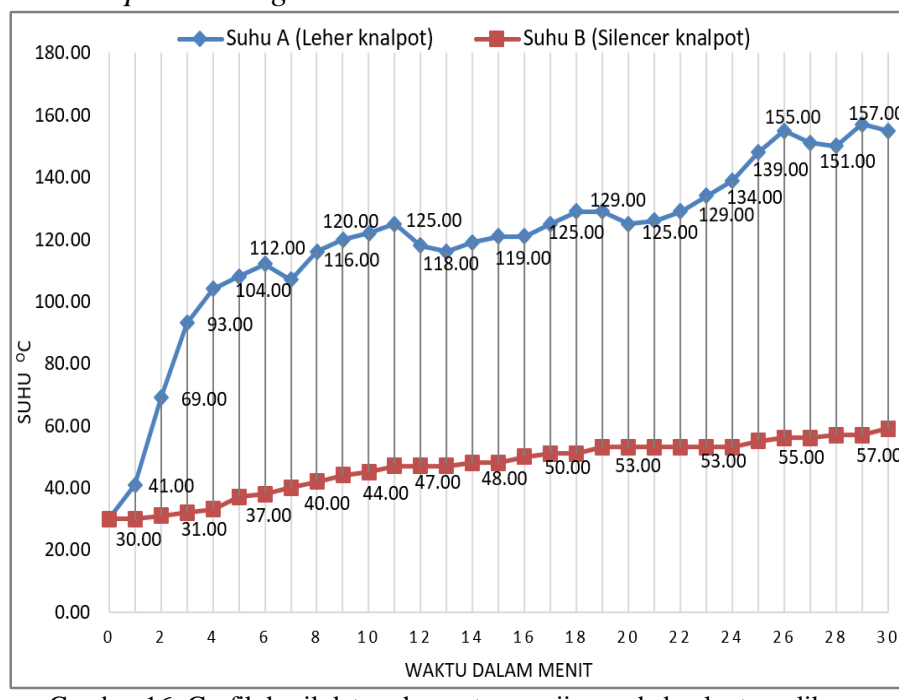

Gambar 16: Grafik hasil data suhu saat pengujian pada knalpot replika dengan kecepatan blower ke-1.

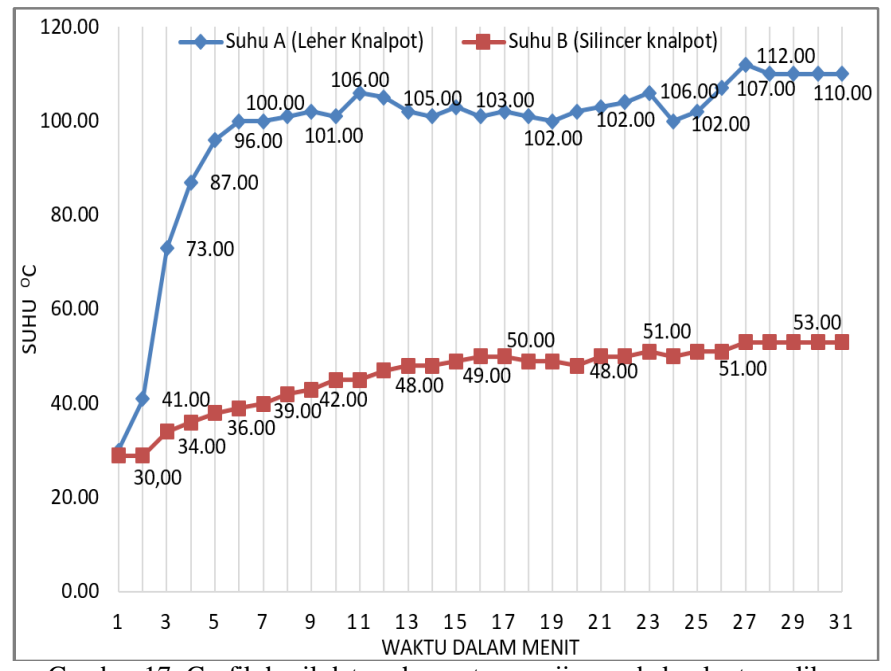

Gambar 17: Grafik hasil data suhu saat pengujian pada knalpot replika dengan kecepatan blower ke-3.

Pada pengukuran suhu knalpot sepeda motor spacy (motor sungguhan) aliran udara tidak berpengaruh terhadap suhu knalpot karena pada sepeda motor makin cepat aliran udara yang melaju semakin cepat juga pembakaran dalam mesin sepeda motor di buat, karena panas knalpot pada sepeda motor berasal dari pembakaran mesin sepeda motor, berbeda dengan knalpot replika panas berasal dari elemen panas yang bersumber dari tenaga listrik, panas pada elemen akan berkurang jika elemen di aliri hembusan angin semakin cepat hembusan angin yang mengaliri elemen panas semakin rendah panas yang di hasilkan oleh knalpot replika yang dapat dilihat dalam gambar 16 dan 17. kecepatan blower lebih rendah suhu yang di dapatkan lebih tinggi.

\section{Pengujian thermoelectrik generator}

Suhu panas termoelektirk dengan adalah $\mathrm{T}_{\mathrm{H}}$ dan suhu dingin adalah $T_{L}$ yang $T_{H}>T_{L}$ atau suhu pada $T_{H}$ harus lebih besar dari suhu $\mathrm{T}_{\mathrm{L}}$ dan perbedaan suhu adalah $\Delta \mathrm{T}$, dimana $\Delta \mathrm{T}$ berasal dari pengurangan dari suhu panas $\left(\mathrm{T}_{\mathrm{H}}\right)$ di ambil suhu Alhidayat : Rancang Bangun Generator Thermal ... dingin $\left(\mathrm{T}_{\mathrm{L}}\right)$ pada thermoelektik, di lihat pada rumus di bawah ini :

$$
\Delta \mathrm{T}=\left(\mathrm{T}_{\mathrm{H}}-\mathrm{T}_{\mathrm{L}}\right), \mathrm{T}_{\mathrm{H}}>\mathrm{T}_{\mathrm{L}}
$$

Pengujian pada terhmoelektrik di lakukan pada beberapa cara yaitu dengan melaukan pengujian tanpa beban dan dengan beban. Pengujian Thermoelectric menghasilkan grafik pada gambar 18. dan 19. dibawah ini.

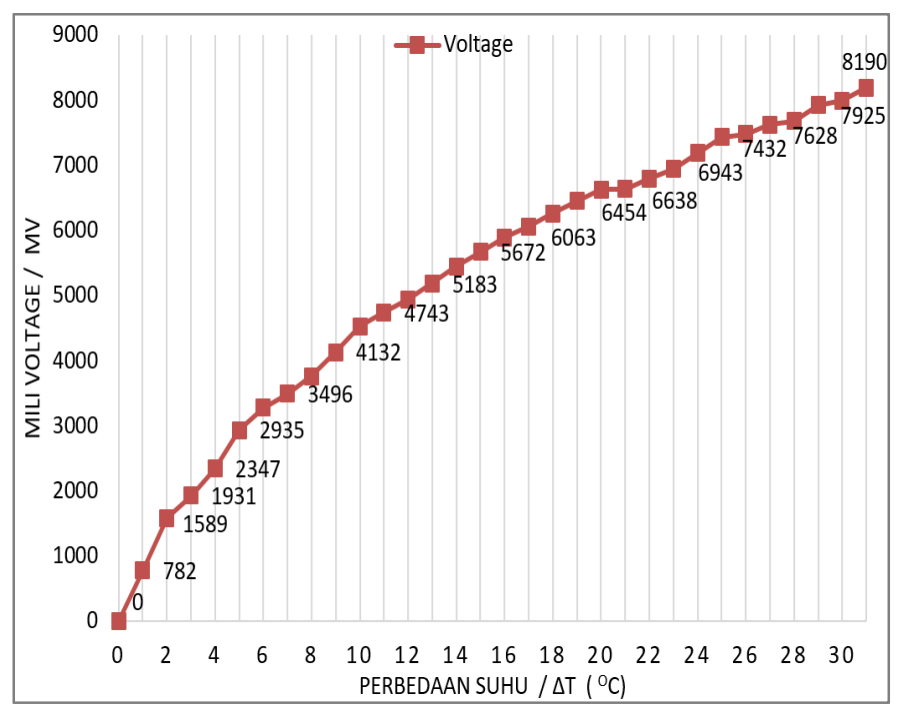

Gambar 18: Grafik perbedaan suhu terhadap tegangan tanpa beban

Pada gambar 18 Perbedaan suhu $(\Delta \mathrm{T})$ pada thermoelectric sangat berpengaruh terhadap tegangan yang di hasilkan, pada pengujian thermoelectric tanpa beban tegangan yang tertinggi di dapatkan pada perbedaan suhu $31{ }^{\circ} \mathrm{C}$ mencapai 8 volt, suhu $\mathrm{T}_{\mathrm{H}} 65^{\circ} \mathrm{C}$ dan suhu $\mathrm{T}_{\mathrm{L}} 34^{\circ} \mathrm{C}$.

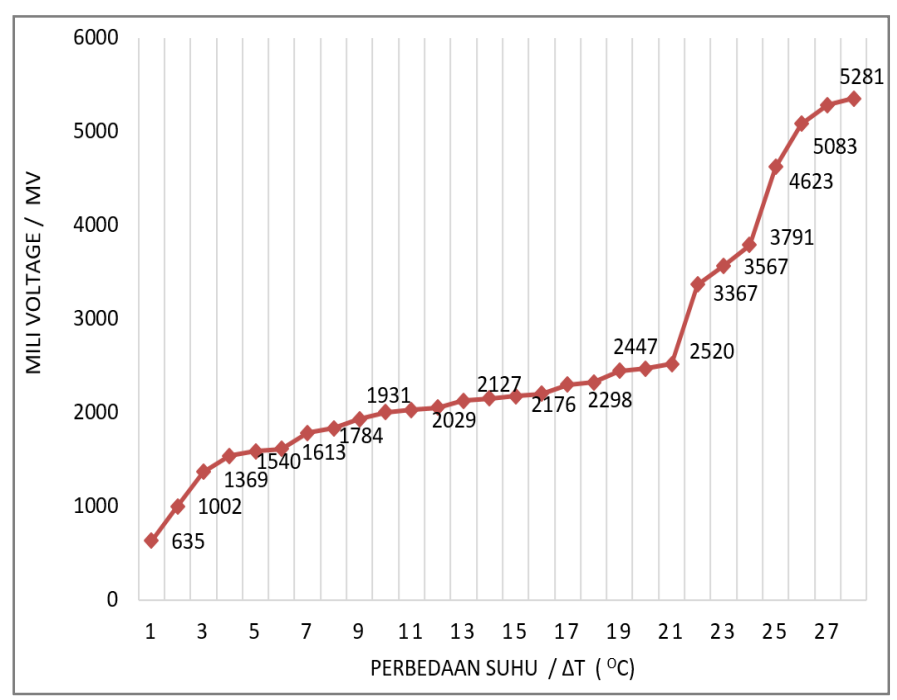

Gambar 19: Grafik perbedaan suhu terhadap tegangan dengan beban

Pada percobaan thermoelectric dengan beban tegangan pada gambar 19. mengalami drop tegangan, tegangan maksimal yang di dapatkan 5 Volt, di karenakan penyesuain daya beban yang di pakai dengan satuan watt. jika lihat dalam

p-ISSN:1693 - 2951; e-ISSN: 2503-2372

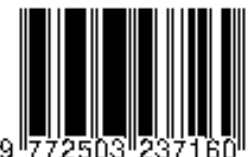


gambar 20. grafik perbedaan suhu terhadap arus listrik arus listrik yang di dapatkan sebesar 0,07 Ampere, daya listrik yang di dapatkan adalah 0,41 Watt, beban yang di pakai adalah lampu led 5volt dengan daya 0,5 watt $\sim 1$ watt, dengan demikian drop tegangan terjadi karena penyesuaian daya beban tersebut.

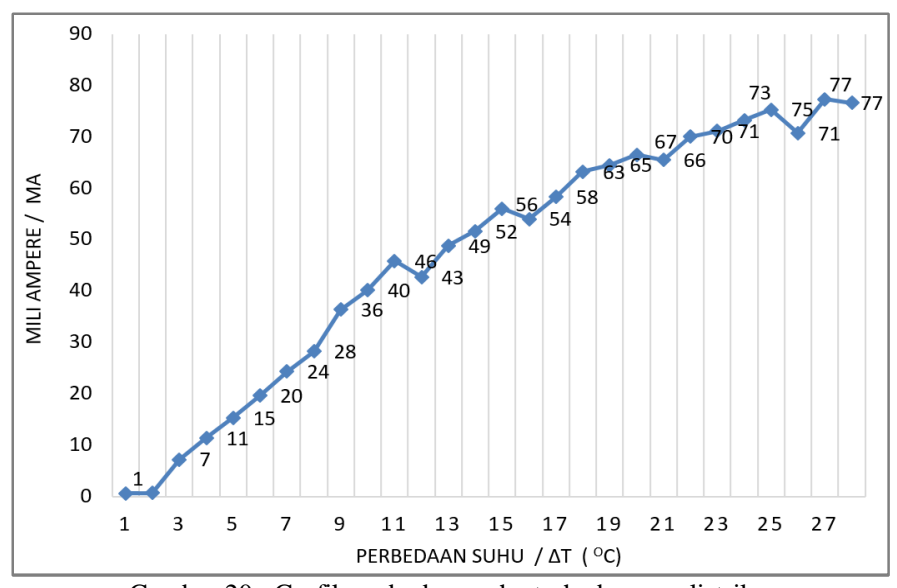

Gambar 20: Grafik perbedaan suhu terhadap arus listrik.

E. Pengujian Thermoelectric dengan beban memakai boost converter

Pengujian Thermoelectric dengan beban menggunakan boost converter, dimana tegangan yang keluran dari Thermoelectric atau di sebut tegangan $V$-in, tegangan akan di proses terlebih dahulu oleh boost converter sebelum di lanjutkan ke beban lampu led 5 volt, tegangan dari boost converter adalah $V$-out.

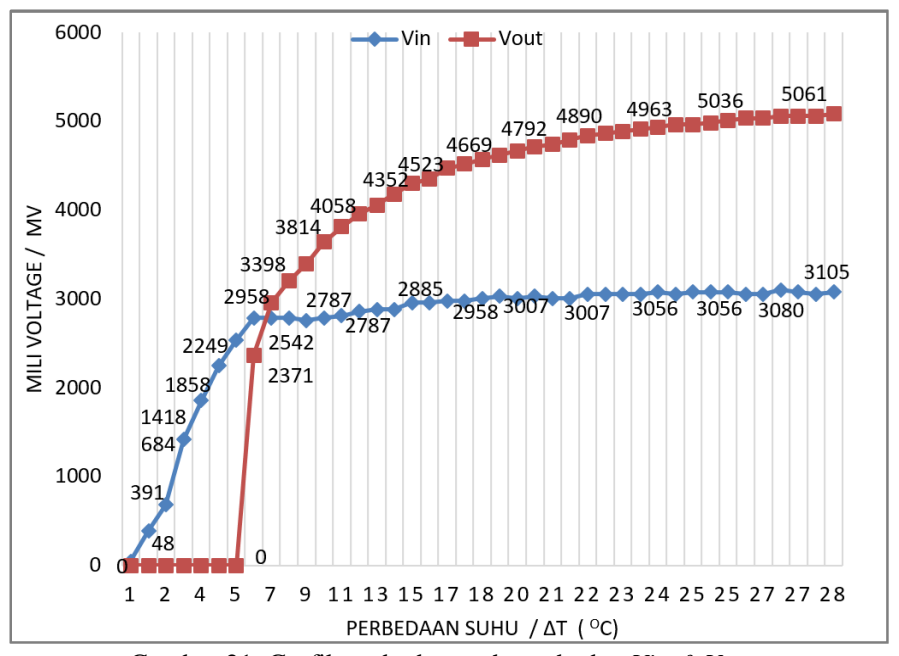

Gambar 21: Grafik perbedaan suhu terhadap Vin \& Vout

Pada gambar 21. grafik perbedaan suhu terhadap $V$-in $\& V$-out, dapat kita lihat perbedaan tegangan yang di dapatkan pada $V$-in dan $V$-out berbeda dalam satu waktu pengujian, pada tegangan keluaran boost converter akan menstabilkan tegangan keluaran dari thermoelectric, boost converter mengatasi masalah variasi tegangan yang dihasilkan oleh thermoelectric, boost converter yang nantinya bekerja secara otomatis dalam menyesuaikan tegangan output dari thermoelectric sesuai dengan tegangan yang dinginkan, terlebih dahulu boost converter di setting sesuai permintaan tegangan yang di perlukan, tegangan yang di setting adalah 5 volt.

Pada $V$-in tegangan sudah dapat di peroleh pada perbedaan suhu $1^{\circ} \mathrm{C}$, dengan tegangan $V$-in adalah $48 \mathrm{mV}$, tetapi tegangan di $V$-out mendapatkan $0 \mathrm{mV}$, karena tegangan yang di butuhkan $V$-in boost converter belum di dapatkan, di perbedaan suhu $6^{\circ} \mathrm{C}$, tegangan $V$-in 2,7 Volt baru tegangan di $V$-out keluar sebesar 2,3 Volt, di mana titik ini $V$-out menghasilkan tegangan terus meningkat sampai tegangan yang di inginkan $V$-out sebesar 5 Volt pada saat tegangan thermoelectric atau $V$-in mendapatkan 3 Volt pada saat perbedaan suhu $26^{\circ} \mathrm{C}$.

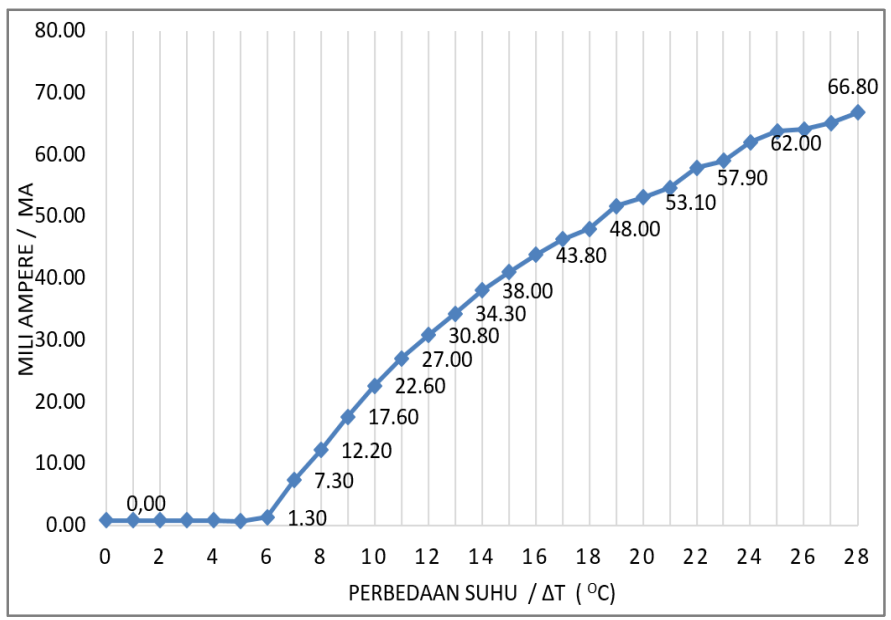

Gambar 22: Grafik perbedaan suhu terhadap arus listrik mengunakan boost converter

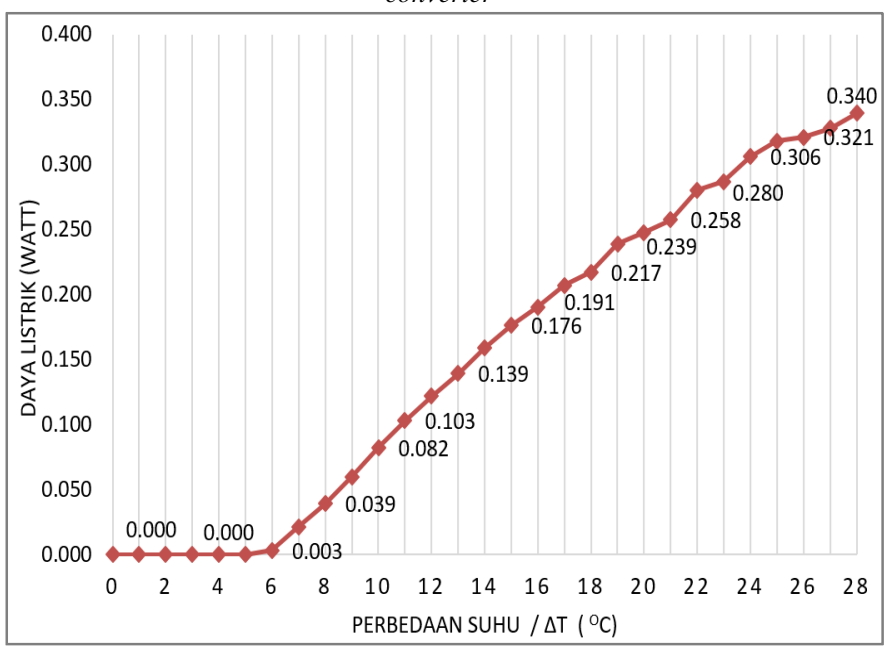

Gambar 23: Grafik perbedaan suhu terhadap daya mengunakan boost converter

Dalam gambar 23. daya listrik yang dihasilkan dengan percobaan menggunakan boost converter di peroleh dari :

$$
\mathrm{P}=\mathrm{V} \times \mathrm{I}
$$

Antara gambar 22. menyatakan arus listrik yang di dapat dan gambar 23. menyatakan daya yang di dapat Dimana $\mathrm{P}$ adalah daya beban dengan satuan watt, $\mathrm{V}$ adalah tegangan dengan satuan volt dan I adalah arus listrik dengan satuan ampere. 


\section{KESIMPULAN}

Dari hasil pengujian dan analisa yang dilakukan maka dapat di simpulkan beberapa pengujian mengunakan TEP1142 T300 sebanyak 4 buah, thermoelectric di susun seri bertujuan agar mendapatkan tegangan yang tinggi, pengujian dilakukan beberapa tahapan yakni pengujian tanpa beban, tegangan tertinggi yang di dapatkan mencapai 8 volt pada perbedaan suhu $(\Delta \mathrm{T})$ antara $\mathrm{TH}$ dan $\mathrm{TL}$ adalah $31{ }^{\circ} \mathrm{C}$ suhu di TH $65{ }^{\circ} \mathrm{C}$ dan suhu TL $34{ }^{\circ} \mathrm{C}$, thermoelectric generator sangat di pengaruhi perbedaan suhu dengan suhu di TL harus lebih kecil di suhu TH, untuk suhu di TL lebih efektif suhu di bawah $40{ }^{\circ} \mathrm{C}$, untuk menstabilkan suhu di TL diperlukan radiator pendingin, selanjutnya pengujian menggunakan beban lampu led 5 volt mengalami drop tegangan, tegangan maksimal yang di dapatkan 5 Volt dengan daya listrik yang di dapatkan 0,41 Watt di arus 0,07 Ampere, pengujian menggunakan boost converter tegangan pada V-out stabil mendapatkan 5 Volt, dimana tegangan thermoelectric V-in harus mendapatkan tegangan 3 Volt. Daya listrik yang dihasilkan dengan percobaan menggunakan boost converter adalah 0,34 Watt. Daya yang di hasilkan sangat kecil sekali karena jumlah modul thermoelectric juga mempengaruhi daya yang dihasilkan, kelebihan dalam pengujian ini kita dapat memanfaatkan panas buang kendaaraan bermotor.

\section{REFERENSI}

[1] Rahbar, K., S. Mahmoud, R. K. Al-Dadah, N. Moazami, D. J. S. "Feasibility study of power generation through waste heat recovery of wood burning stove using the ORC technology."Ashmore and society (2017).

[2] Sasmita, Sandy A. "Alternatif Pembangkit Energi Listrik Menggunakan Prinsip Termoelektrik Generator" Jurnal of Tesla Vol. 21 No. 1.2019

[3] Andreoni V, Galmarini S. European CO2 emission trends: a decomposition analysis for water and aviation transport sectors. Energy. 2012;45(1):595-602.

[4] Romina Rodriguez, Matthias Preindl, Ali Emadi, and James Cotton, "Maximum Power Point Tracking for Thermoelectric Generators with High Frequency Injection", IECON 2015 conference, Japan, pp. 41274132, 9-12 November, 2015.

[5] Wikipedia.org "Thermoelectric generator" [online] https://en.wikipedia.org/wiki/Thermoelectric_generator. 2021.

[6] Adroja, Mr Nikunj; B.Mehta, Prof Shruti; Shah, Mr Pratik. "Review of thermoelectricity to improve energy quality". 2 - Issue 3 (March-2015). JETIR.

[7] Babu, J. Kumar. "The Design of a Thermoelectric Generator and Its Medical Applications" ResearchGate. April 2019.

[8] Rusli, Adriyani. Djabbar, Rahmania. "Konversi Energi Panas Menjadi Energi Listrik Dengan Menggunakan Generator Termoelektrik".Jurnal Logitech. 2020.

[9] Wikipedia.org "Energi termal" [online] https:// en.wikipedia.org/ wiki/Thermoelectric_generator. 2021.
[10] Wirawan, R. "Analisa Penggunaan Heat Pipe pada Thermoelectric Generator." Skripsi. Teknik Mesin. FTUI. 2012.

[11] Masrufaiyah, Sulistiono. Tri J. "Analisa Pengaruh Jumlah Plug Pada Kondenser Terhadap Effisiensi Dan Heat Transfer Yang Hilang Di PLTU unit 3 dan 4 PT. PJB UP. Gresik" Jurnal wahana teknik. Vol. 7, No. 1. Juni 2018

[12] Culp, A.W. " Prinsip-Prinsip Konversi Energi", terjemahan Darwin Sitompul, Erlangga, Jakarta. 1996.

[13] Cengel, Yunus A. "Heat Transfer : A Practical Approach Second Edition". McGraw-Hill. New York. 2003.

[14] Mojiri, "Spectral beam splitting for efficient conversion of solar energy-A review," Science direct. 2013.

[15] Taylor, R.A. "Applicability of Nanofluids in High Flux Solar Collectors". Journal Of Renewable And Sustainable Energy 3, 023104. 2011.

[16] Riffat SB, Ma X. "Thermoelectrics: A review of present and potential applications". Appl Therm Eng. 2003.

[17] Sahin, Ahmet Z. Yilbas, Bekir S.. "Performance analysis of a thermoelectric power generator under volumetric constraint". Transactions of the Canadian Society for Mechanical Engineering, Vol. 40, No. 1. March 2016.

[18] Power practical "How Do Thermoelectrics Work?" [online]. https: //powerpractical.com /pages /how -dothermoelectrics-work. 2021.

[19] Cengel YA, Boles MA. "Thermodynamics: An engineering approach". 6th ed. McGraw-Hill press, New York. 2008.

[20] Ismail, Basel I. Wael H. Ahmed. "Thermoelectric Power Generation Using Waste-Heat Energy as Alternative Green Technology". Recent Patents on Electrical Engineering. 2010. 
\{Halaman ini sengaja di kosongkan \} 